\title{
Centroamérica y Bélgica: curiosas interferencias a nivel de jefatura de Estado... (entre la suerte y el destino asumido)
}

Victor Valembois

\begin{abstract}
RESUMEN
Comparo Costa Rica y Bélgica en ciertos puntos. Algo tiene de inusual porque las corrientes geopolíticas actuales los alejan. Sin embargo, entrelazado con reflexión sobre la temática de la suerte versus el determinismo, presento una serie de curiosas interferencias entre los dos países, partiendo del hecho de haber tenido en más de una oportunidad una misma jefatura de Estado.
\end{abstract}

Palabras claves: Bélgica; relaciones; suerte, jefe de estado.

\begin{abstract}
I'm comparing Costa Rica and Belgium in several points, despite the fact that the geopolitical trends divide them more and more. But here, in clear and permanent allusion to the topic of fortune versus determinism, I present some strange cases of interaction between both countries, starting from the fact that at times both have shared the same head of state.
\end{abstract}

Key words: Belgium; relations; fortune, head of state.

Dios corta el mazo y reparte las cartas, pero es el hombre el que las juega.

W. Shakespeare

Para Nuria Leiton y Maruja Cortés, otros puentes vivos entre Costa Rica y Bélgica.

\footnotetext{
* $\quad$ Doctor en Literatura Española por la Universidad Complutense de Madrid. Docente jubilado de la Universidad de Costa Rica. Investigador. valembois@ice.co.cr
} 


\section{Contextos y circunstancias}

Mi título no postula un utópico o futurista acercamiento transcontinental, ajeno totalmente a las corrientes geopolíticas actuales, sino que presenta una serie de curiosas interferencias, en el jefe de estado o muy cerca de él, entre Costa Rica y Bélgica. Procederé a describir no menos de cuatro casos concretos.

Los hechos verídicos relatados aquí también subrayan la dicotomía entre casualidad y determinismo. Por allí anda la diosa Fortuna, pero además existe el libre albedrío. Lo anterior es válido tanto en lo personal como en lo colectivo. Ahora bien, al igual que a mi amigo Constantino Láscaris, me asiste la ventaja de poder comparar horizontes. Si se ha vivido entre dos continentes, se siente mejor el clima grupal que prevalece en determinadas latitudes. Del lado nórdico, europeo, siente uno que prevalece más aquello de "la fortuna ayuda a los audaces", como nos inculcaron, hasta en latín. Del lado tropical se palpa más aquello de "ojalá" o "si Dios quiere", tan insistentemente repetido, que aparte del contexto religioso, reflejan actitudes de fatalismo, de dependencia ajena, aprendidas en la comunidad. No lo supongo yo, lo demuestra Carmen Naranjo en Cinco temas en busca de un pensador, a partir de estas expresiones como también del consabido idiay ${ }^{1}$, a las que valga la ocasión, añadiría el muy costarricense por dich $a^{2}$.

De paso, hago esta investigación animado, en parte, por otra circunstancia, feliz y aprovechada: en el año 2008, Centroamérica (incluyendo Costa Rica) y Bélgica celebran 150 años de formales relaciones diplomáticas.

\section{Curiosos nexos antes de 1517}

Entre la hazaña de 1492 y 1517, metiendo en contacto la antes llamada "Flandes" (y ahora, mutatis mutandis: Bélgica) y el área circuncaribe, hubo una interferencia del tipo que nos interesa. En los últimos años, gracias al arte, pudimos acercarnos un tanto más cómodo a esa historia. Tanto por el cine como por la literatura hemos visto subrayado el sorprendente acercamiento geográfico, trasatlántico, que estoy haciendo. En la pantalla, la grande y la chica ${ }^{3}$, con imágenes

1. Véase mi estudio: "Sacando punta al lenguaje: la expresión idiay" (glosa de un estudio de Carmen Naranjo), Colección "Escritores latinoamericanos", vol. 3, 51-82, Ed. Promesa, Costa Rica, 2007.

2. Del Diccionario de la Academia se aprende: dicha. Del lat. dicta, cosas dichas, pl. n. de dictum, con el sentido de fatum, suerte, destino, en lenguaje vulgar, según la creencia pagana de que la suerte individual se debía a las palabras pronunciadas por los dioses al nacer el niño.

3. Remito al reciente éxito de taquilla, a partir de la película de 2001. 
y con imaginación nos metimos en la vida dramática de "Juana la Loca"; lo mismo, por una novela de Gioconda Belli ${ }^{4}$, vemos, sentimos a esta misma persona de carne y hueso, transformada en personaje literario. Dentro de las posibilidades de cada género, inserto cada uno en vastos circuitos comerciales transnacionales, ambos casos mantienen un razonable respeto por la verdad historiográfica.

No entraré en el detalle de ninguna de las dos producciones evocadas, pero calzan en la extraña relación que estoy subrayando: no fue ruleta rusa sino consciente búsqueda de alianzas y de poder. El enlace matrimonial $\mathrm{Fe}$ lipe el Hermoso y Juana la Loca, hace surgir un eje norte-sur, entre Flandes y España. De allí que en las dos primeras décadas del siglo XVI, bajo un gobierno político en estrechas interferencias con Flandes, se llevan a cabo importantes descubrimientos de lo que después se llamaría "América", concretamente el área de las Antillas en Centroamérica. Por la misma buscada unión dinástica, construcción completamente humana, el hijo de la citada Juana la Loca, nacido por gracia de Dios un 24 de febrero de 1500, en Gante, fue proclamado rey de España. Llega a su "destino" (palabra de doble sentido, constato ahora), a fines del 1517.

\section{Carlos Quinto: asumir su propio destino}

Por lo anterior, sorprendente pero verídico, forjado y nada casual, durante casi dos siglos la futura Costa Rica (en 1821) y la Bélgica por venir (en 1830) formaban parte de un solo imperio "donde no se ponía el sol" (metáfora que después copiaron los ingleses). Fue tremendo el encontronazo en España. Don Carlos llegó a Madrid con su enorme séquito de flamencos de por allá, quienes, aparte de ser extranjeros, por lo visto tenían sangre de lúpulo en las venas (ver: Camino de Santiago, la novelita de Alejo Carpentier ${ }^{5}$ ). Por esas características, además de cobrar alegremente impuestos, se hicieron indeseables.

Igual o peor fue el choque cultural entre los gobernados en América y su gobernante. En efecto, no cabe perder de vista (como lo hace sistemáticamente más de una historiografía)

\footnotetext{
4. Remito a la novela El pergamino de la seducción, que leí en la co-edición de Seix Barral y Anama, 2005. Existe otra edición, también de Seix Barral, del 2007, en edición de bolsillo.

5. Remito a mi trabajo: "Alejo Carpentier y su peculiar "pica en Flandes" (Lectura flamenca de su obra El camino de Santiago)", en Federico García Lorca et Cetera, Estudios sobre las literaturas hispánicas en honor de Christian De Paepe, por N. Delbecque, N. Lie, B. Adriaensen (eds). Leuven University Press, Bélgica, 2003, pp. 517-523.
} 
que forajidos conquistadores como Hernán Cortés y Pedrarias, para citar solo los más importantes en el área centroamericana, debían obediencia a este rey forastero. Eran colosalmente diferentes. Por un lado, ese mozalbete imberbe, humanista formado por el viejo Erasmo en función de las ideas de una "milicia" cristiana universal y el pacifismo; por otro lado, esos barbudos y rudos... para no decir analfabetos, la mayoría. Un punto unía esos figurantes en la historia: todos estaban en el cruce entre la Edad Media y el Renacimiento, entre un mundo europeo y una perspectiva de universo redondo que poco después probaría Magallanes. Tenían conciencia de una misión civilizadora, sinónimo entonces de "cristianizadora", aunque fuera a "cristazos", como acertadamente interpretó Miguel de Unamuno esta auto-asumida voluntad de "destino manifiesto" (Monroe adelantado...). Esa era la tarea imperiosa frente al resto del mundo, "la parte bárbara" como en sus mapas lo señalaba Mercator, otro flamenco de esa misma época. Los unía la Utopía de Tomás Moro, ésta última, por cierto germinada una noche de verano, frente a los muelles del puerto de Amberes, Bélgica. Si la obsesión de Cortés era la de quemar sus naves, ¡ni un paso para atrás!, el lema de Carlos $\mathrm{V}$, dándole vuelta a la advertencia de Hercules, era plus oultre, ¡más allá!

Ese encuentro del Viejo Continente con el Nuevo Mundo, y por deducción de los dos países que nos ocupan preferentemente, de Costa Rica y de Bélgica, tuvo en la figura del citado Carlos su razón de estado. Llegó de repente a ser heredero de vastos territorios en los antiguos "Países Bajos" (otra cosa cubre ese nombre ahora), así como partes de la actual Italia, España, Alemania... y toda la América española. En sus $M e-$ morias del fuego, Galeano señala que "el monarca devoraba hombres y los hombres cagaban monedas de oro en el Jardín de las Delicias del Bosco". En el vértice europeo de esa primera parte del Siglo XVI estaban Bruselas y Madrid, y Carlos V, sin asiento fijo de gobierno, cantidad de veces se fue de un lado para otro con su corte. Costa Rica ya tenía nombre pero no existía todavía sino como parte de la Capitanía de Guatemala; era un pañuelito entre episodios de conquista panameña y nicaragüense del temible Pedrarias Dávila. "Aunque usted no lo crea", este terruño suyo y el mío, entre 1517 y 1555 se encontraron jurídicamente gobernados por un mismo Jefe de Estado, un flamenco.

En Costa Rica quedan huellas de esa época turbulenta y definitoria para ambas naciones. Hay realmente casualidades en la vida, como esos nexos belgas en el Marqués de Peralta, que durante más de cincuenta años fue Ministro Plenipotenciario de Costa Rica y por cuyo intermedio allí se compró la Escuela Metálica, entre otros. Pues bien, aparte de estar 
felizmente casado con la Juana belga que canta Darío, su título nobiliario remonta nada menos que a 1524 y se debe... a Carlos V. Es también el acucioso don Manuel, en su labor de defensa literal de Costa Rica, entre otros a partir de investigaciones en el Instituto Geográfico de la capital de Bélgica, quien hizo gran parte de recopilación sobre el valor histórico del primer asentamiento español en territorio costarricense, mucho antes de Cartago y de Esparza. En homenaje precisamente al mismo Emperador, fue la "Villa de Bruselas". Solo duró contados años desde 1524, porque el citado Pedrarias la mandó despoblar.

Esas vueltas o "casualidades" de la historia dejan lecciones. Interpreto que don Manuel buscó su realización personal bastante lejos del terruño que lo vio nacer, allí sí, completamente involuntario (era hijo natural). También Carlos V, en 1517, hubiera podido negarse a la azarosa travesía que lo llevó de Vlissingen (ahora en los Países Bajos) a una playa cerca de Santander; y hacia el final de su vida, gastado por tanto trajín, fue en Bruselas, en 1555, donde renunció voluntariamente al trono que lo hacía también rey en Costa Rica...

\section{"Lo mismo pero distinto", hasta 1713}

Vale también este título, inspirado en peculiar modismo atribuido a don Pepe Figueres: a Carlos Quinto lo siguió Felipe II, su hijo mayor, con lo que técnicamente, para sus dominios, aquí concretamente la idea central del mismo Jefe de Estado, mantuvo vigencia por ambos lados del Atlántico: ¡faltaban más de ciento cincuenta años! Apenas ascendido al trono el vástago, pareciera que Costa Rica y Bélgica corrieron similar suerte, de bancarrota y contrarreforma. Distinto resultó sin embargo el interés de la Corona en esas partes del inmenso reino: si entonces en el trópico se acentuó el aislamiento que tanto caracterizaría a esta provincia, en cambio a "Flandes" le mandaron unos diez mil "tercios", metiendo sangre y fuego en todas partes. Hasta en el mismo Quijote se narra la tremenda barbarie de matar a los Duques de Egmont y de Hoorn en plena Plaza de Bruselas: el Duque de Alba, pese a toda la fuerza bruta que utilizó, no se dio cuenta de que estaba socavando bases del mismo imperio.

Entre Costa Rica y Bélgica, a pesar de todo quedaron unos nexos, llamémoslos indirectos: por un lado, entre los pocos, poquísimos libros que circulaban en este trópico estaba la Biblia, impresa en Amberes gracias a un real monopolio concedido por el Católico Rey a Cristóbal Plantijn, en prensas que hace poco fueron declaradas patrimonio de la humanidad. Por otro lado, hasta la más folklórica historiografía sobre esos decenios de dominio español dan cuenta de que entre los gobernadores españoles más 
de uno se había fogueado en Flandes. Así consta también en las amenas y bien escritas Crónicas coloniales de Ricardo Fernández Guardia menciona a varios gobernadores. Citemos, simplemente, a Juan de Echáuz y Velasco (1624-1630), Juan de Villalta (1630-1634), Gregorio de Sandoval (1636-1644), Juan Fernández de Salinas y de la Cerda (1650-1659), Juan López de la Flor (1665-1674), Manuel de Bustamante y Vivero (1694-1702) y Don Lorenzo Antonio de Granda y Balbín (1707-1712). No son pocos... Quedaría por investigar, por ejemplo en tecnología, en costumbres y demás ciencias, la influencia recíproca de este largo período. Hasta en el mismo lenguaje hay huellas, ya no digitales sino guturales... No será superfluo que la palabra para moneda "costarricense", el cacao, ahora se utiliza también en Flandes y que el término "filibustero", tan connotado hasta en el mismo siglo XXI en Costa Rica, tiene su origen en vrijbuiter, de mi idioma materno.

Hablando de interferencias entre idiomas, ¿sabía usted que el término lotería proviene de loterij en neerlandés? Este sistema muy en boga, ahora se conoce más para la atribución fortuita de premios, pero durante siglos, se utilizaba también para suerte (buena o mala), entre otros en asignación de labores y para la conscripción militar. El inglés, el ruso y el alemán, entre otros, testimonian todavía de esa práctica del sorteo, generalizada en Flandes en tiempos de Carlos V. No por casualidad un tipo de imprenta especial, los naipes, en concreto por una fábrica en Turnhout (Flandes) entonces, durante siglos mantuvo renombre internacional. Ya en 1532, la palabra "lotterie" se conoce en francés, italiano y otros idiomas occidentales. Ahora "lotto" es de dominio universal. ¡Y que tenga suerte!

Lo cierto es que la madeja ya no daba para más. Lo que inició poco menos que como cordón umbilical con un mismo jefe de estado, flamenco pero reinando también en Costa Rica, se rompió: entre las dos partes, si bien hubo, no por décadas, sino desde 1517 hasta inicios del siglo XVIII todavía, una unión oficial entre partes de un mismo reino, esta unión oficial, cada vez más endeble y artificial, se rompió sin siquiera consultar las partes. En 1713, con el Tratado de Utrecht (lo escribo con " $t$ " final, y no como aparece en mucha historiografía antigua), con motivo de la guerra de sucesión en el trono español, Bélgica y Costa Rica fueron formalmente separados, quedando solo la última bajo corona hispana: los llamados "Países Bajos Españoles" (prácticamente la futura Bélgica) pasó al Sacro Imperio de Austria.

Nada bueno producen ni la supuesta "mala suerte" ni la idea de predestinación, aunque sea entre opuestos al protestantismo, de lado y lado del Atlántico. Menos provecho todavía trae la nostalgia. Inexorablemente, 
para el imperio español vino el declive. Todavía en 1910, Eduardo Marquina escribió poéticamente al estilo de su coterráneo Manrique. En Flandes se ha puesto el sol se estrenó en Madrid, llena de ecos de aquel que todo tiempo pasado fue mejor. La obra escenifica esos tiempos del siglo XVI y XVII en que los españoles se sentían en casa, tanto en Bélgica como en Costa Rica. Evoca el conflicto interior de Diego de Acuña, capitán que se casa con Magdalena, una flamenca, animando su vida en la esperanza de su hijo (sangre "belga" y española mezclada). El tiempo no solo corre, como decimos, sino que huye: así ya lo percibían los romanos (fugit irreparabile tempus): o lo aprovecha uno, o como los ríos, se pierde en el océano. La gran feminista "tica" Ángela Acuña cantó las glorias, entre otros de Brujas en 1908 y en 1926, con base en la obra Brujasla-Muerta, de 1892, donde Georges Rodenbach inmortalizó esta ciudad. En otra parte efectué un análisis de esta magnífica obra, llena de brumas pero no de determinismo y he apuntado su acogida extraordinaria entre los costarricenses de las primeras décadas del siglo XX. ${ }^{6}$
Yo sé de más de otro Acuña, con raíces ticas y amarras en Bélgica, después... Pienso no solo en, sino en diversos emigrados del mismo apellido que, por estudio o por trabajo, dejaron su huella allá. También Miguel Acuña Valerio contribuyó a correr el velo sobre el punto que en seguida abordaré. ${ }^{\text {¡Hay mucho hilo suelto }}$ todavía en el tejido bilateral!

\section{Una Primera Dama belga en Costa Rica: casualidad y misión asumida}

Hace más de quince años, prácticamente en la miseria y en una sala común del Hospital Dr. Calderón Guardia, creado por su esposo, murió Yvonne Clays Spoelders (1910-1994). Fue su legítima esposa, al casarse en Amberes en 1927 y por ese hecho llegó a ser ciudadana también belga, Primera Dama de Costa Rica cuando él asumió la presidencia, entre 1940 y 1944. Como lo muestra con creces Miguel Acuña, en medio de vaivenes políticos y con el gran Océano de por medio, esta mujer asumió su destino, ¡nada menos que una Antígona en el trópico! Ahora bien, dados los casos paralelos, entre antecedentes $y$

6. “ ¿Una estrella fugaz en el firmamento literario?”, Revista Nacional de Cultura, UNED, Costa Rica, diciembre de 1999, pp. 23-33.

7. Refiero concretamente a su libro Ivonne Clays, testigo de la neurosis de una administración, editado por cuenta propia, Costa Rica, 1995. Miguel Acuña Valerio fue miembro fundador y un tiempo presidente de un gigantesco esfuerzo de acercamiento entre nuestros dos pueblos: FUBELCO (Fundación Belga-Costarricense). 
continuados, se dan hasta la fecha en América Latina seis expedientes de primeras damas de origen belga. Con base en el eurocentrismo que durante siglos prevaleció, podría pensarse que fueran simplemente flores de palacio, otra especie de "producto" de lujo, materia de exportación, simples acompañantes de sus maridos que se especializaron en Bélgica.

Pero se da la casualidad -capricho de la diosa Fortuna- que, después de comer perdices, no fueron necesariamente felices. Fue la suerte que trágicamente le tocó (allí sí, en forma absolutamente negativa) a María Carlota. Nacida en cuna de oro, siendo hija del primer Rey de Bélgica, se encaminaba a ser Emperatriz de México. Efectivamente lo fue, pero durante muy poco tiempo. Testigos mudos lo son todavía los jardines y el palacio en Chapultepec. En el español de Costa Rica la palabra mariachi proviene de esta época, por mariage en francés. Por desgracia, su marido, Maximiliano de Habsburgo, Archiduque de Austria, murió acribillado por las balas juaristas al amanecer del 19 de julio de 1867. Un tanto lo buscó. Más que un suceso para los periódicos, quedan huellas: por ejemplo, Aura y otras obras de Carlos Fuentes todavía nos narran el horror. Carlota se trastornó, la pobre, transformándose en una especie de otra Juana la Loca. Blanche Cousin constituye el segundo ejemplo. Se casaron en Nicaragua, cuando ella tenía quince años apenas y gestaron una numerosa prole. Pero su marido, José Santos Zelaya, presidente de Nicaragua, tuvo que exilarse en 1909. Mi general hizo maletas y se fueron para Bruselas, de donde era originaria la famosa Blanca que hasta Rubén Darío interesadamente cantó. Un caso anterior, feliz, fue, en el siglo XVI, el gobernador Juan López de la Flor casado con la joven belga Margarita Watecant. Casos muy recientes son las esposas Elianne Karp y Anne Malherbe, de los (ex)presidentes Toledo y Correa, de Perú y Ecuador respectivamente. Todos menos dramáticos, "por dicha".

La tercera muestra, siendo belga y también costarricense, debería ser la más conocida, pero no es así, en parte por mezquindad, en parte por intereses políticos. Pero es allí justamente donde engancha el caso doloroso de esta persona dentro del eje central del presente trabajo. Es que "Doña Ivonne", como cariñosamente le ponen los que la conocimos, no fue simplemente "esposa de", sino una personalidad hecha y derecha, de méritos comprobados en el quehacer diplomático y de seguridad social en Costa Rica. Consta así en escritos y 
estudios de envergadura histórica, como los de Fernando Soto Harrison y de Jorge Sáenz Carbonel1 ${ }^{8}$.

No es este el lugar para demostrar que mucho más allá de aquello de "detrás de un hombre importante hay una mujer importante", doña Yvonne fue diplomática, organizadora de actividades de salud pública, intérprete para su marido en Washington, creadora de la segunda orquesta sinfónica del país (véase también el estudio de Virginia Zúñiga Tristán) y un largo etc. Last but no least, si mis lectores y yo disponemos de seguro social, se debe entre otros a la tesonera labor de esta gran dama. ¿Será suficiente esta enumeración sucinta para que esta señora tica-belga figure también en el presente trabajo? Cierto, en sentido estricto ella nunca fue jefe de estado, pero tampoco fue solamente "la mujer del Doctor".

\section{Entre la suerte fatalista y la construcción consciente de un destino}

Nos ha ocupado un contexto trasatlántico y bilateral sobre varios siglos. Con este ejercicio he pretendido poner en evidencia que en los cinco siglos desde el descubrimiento del Nuevo Mundo, en más de un momento ha habido coincidencia o hasta identidad, entre Costa Rica y Bélgica en la más alta esfera de la jefatura del Estado. Confío haber logrado este objetivo, el cual desde luego invito a sopesar, criticar, completar.

Pero también, a medida que iba redactando, la caprichosa musa Clío me confirmó, con cada párrafo más claramente, qué cierto resulta aquella aseveración de Ortega y Gasset: "yo soy yo y mi circunstancia". Todos estamos ante el dilema, a veces en forma imprevista para uno (como el propio nacimiento: la Geworfenheit), pero otras muchas veces, como lo subraya el epígrafe del gran Shakespeare, cada uno puede y debe asumir sus propias decisiones y responsabilidades. Cabe posesionarse deliberadamente, creativamente, auguro que positivamente de su destino.

En el ajedrez de relaciones entre Costa Rica y Bélgica alea iacta est, la suerte está echada, pero yo sabré asumir mi función de peón.

8. Refiero al libro ¿Qué pasó en el 48? de don Fernando (publicado por la UNED). Jorge y yo, junto con otros, estamos editando un libro conmemorativo del 150 aniversario de las relaciones diplomáticas entre Costa Rica y Bélgica, en publicación también por la UNED. 
